\title{
DUPLICATION OF SMALL INTESTINE
}

\author{
H. S. KirThi Singha, M.A., M.B., B.Chir., F.R.C.S., F.R.C.S.E. \\ Colombo, Ceylon
}

'Duplication' has been used as a general term to include certain congenital abnormalities of the alimentary tract. These are characterised by some distinctive features:-

I. They are hollow structures possessing all or some of the layers of the normal intestine.

2. They are intimately adherent to the adjoining intestine.

3. They lie between the layers of the mesentery on the mesenteric side of the intestine.

In general these abnormalities are either tubular or spherical in shape. The latter have received a variety of names in the literature, e.g. enterogenous cysts, enteric cysts, inclusion cysts and giant diverticula. Duplications are encountered throughout the alimentary tract from the mouth to the anus and are most commonly found in the small intestine. Many theories have been put forward in an attempt to explain these duplications. Lewis and Thyng (cited by Ladd and Gross, 1940) frequently found diverticula in the foetal alimentary tracts of pigs, rabbits, cats, sheep and man. These knob-like outpockets of the intestinal wall normally regressed, but the pinching off of one of these structures, separating it from the normal intestinal wall, was thought to be the mode of formation of these abnormalities. Bremmer (I944) attributed duplication to a failure of cystic spaces, which convert a solid stage of the intestinal canal into a tube, to join up with the main lumen. However, apart from the oesophagus and the duodenum, no such solid stage has been described in the development of the normal intestine; in fact there is some doubt as to whether such a stage is present even in the two sites mentioned above (Frazer 1940). Another possible explanation is that duplications represent a localised form of twinning. Experimentally it has been found that various degrees of twinning may be produced by chemical and physical agents applied to the developing embryo (Needham, 1942). Further studies in this direction may therefore lead to a more satisfactory explanation of the phenomenon of duplications of the alimentary tract.

The following case is of special interest in its mode of presentation:-

\section{Case Report}

History. The patient, a schoolboy aged I3 years, was admitted to the General Hospital, Colombo, with a history of abdominal pain of 4 days' duration, which had started suddenly in the centre of the abdomen and had, some hours later, shifted to the right iliac fossa. The patient had vomited once soon after the onset of the pain and since then complained of nausea. His bowels had opened once daily after the onset of the attack but he was constipated on the day of admission. He had also developed a slight burning sensation on micturition. He complained of no other symptoms and had been quite well and fit prior to this illness.

On Examination. $\mathrm{He}$ was a well-nourished, normally developed boy. His general condition was satisfactory. The pulse rate was 30 , the temperature $100.8^{\circ} \mathrm{F}$. and the respiration rate was 28 per min. The tongue was furred and dry and no enlarged glands were palpable in the neck. There were no external herniae, the abdomen moved slightly with respiration and there was a minor degree of distension. There was generalized guarding and tenderness to palpation, most marked in the right iliac fossa. No masses were palpable. The bowel sounds were absent. There was marked tenderness in the rectovesical pouch on rectal examination.

A diagnosis of peritonitis due to a perforated appendix was made.

Operation. Under general anaesthesia a right oblique muscle cutting iliac incision was made. There was just over half a pint of blood contaminated by mucoid material in the peritoneal cavity. The terminal ileum showed duplication, there was a perforation of the bowel and a ruptured, subserosal hematoma in the middle of the duplicated segment. The double-barrelled loop of ileum was resected and an end-to-end anastamosis performed about $I$ inch away from the ileo-caecal valve. The fluid in the peritoneal cavity was removed by suction and gauze swabbing. The abdomen was closed with drainage of the peritoneum.

Progress. Intravenous fluids (including I pint 


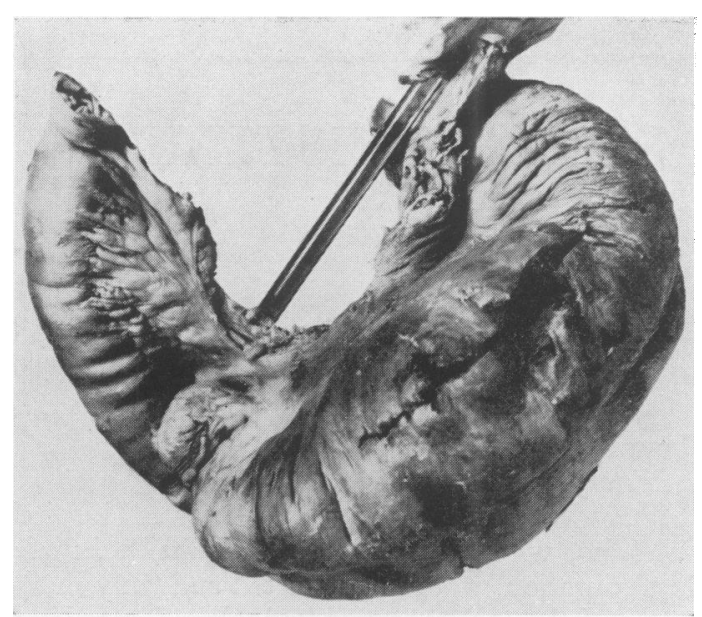

FIG. I.-Photograph of specimen showing duplication of the small intestine.

of blood) and gastric suction were maintained until the bowel sounds were heard ( 48 hours). Penicillin and Streptomycin were administered for 7 days. The drain was removed on the second day after operation. The patient made an uneventful recovery and was discharged on the I $9^{\text {th }}$ day after operation.

Investigations. Barium meal and screening were carried out on the day before his discharge from hospital. This showed 'no abnormality of the gastro-intestinal tract.'

Pathology. (Professor G. H. Cooray)-' The specimen (Fig. I) consisted of 10 inches of ileum, to the mesenteric side of which was a duplicated segment about 8 inches long. The proximal end of the duplication was in communication with the lumen of the ileum, while distally it ended in a blind sac. A large subserous hematoma which had ruptured was present over the duplicated segment. On opening into the bowel it was seen that there was a perforation of the intestinal wall of the duplicate opposite the hematoma.'

Histology. "The tissue at the edge of the perforation shows normal small intestinal mucosa. No heterotopic mucosa was found.'

Comment. Duplications of the alimentary tract are not common but a series of 68 cases have been described by Gross (I953), at the Boston Children's Hospital. The majority of these presented before the age of three $(82 \%)$.

In the region of the ileo-caecal valve, the commonest site for their appearance, duplications produce features which may be grouped as follows:-

I. Pain produced by distension of the duplicate.

2. Obstructive symptoms due to increasing external pressure on the normal segment of intestine.

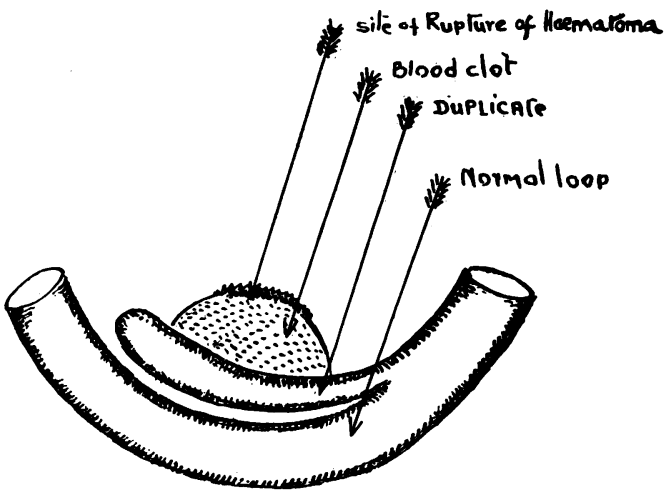

FIG. 2.-Diagrammatic representation to illustrate the्ठ anatomy of the specimen.

3. Haemorrhage into the intestinal tract due tow interference with the intestinal blood supply lead- -0 ing to sloughing of the mucosa, or to ulceration of ${ }^{\omega}$ heterotopic gastric mucosa lining the duplicateo (Wooler, 1950).

4. Fisher (1950) mentions bleeding into the peritoneal cavity as a possibility although his view? was not substantiated by any case record.

The case described here is most unusual as $\vec{\theta}$ perforation occurred in the duplicate in the absence of gastric heterotopia. This was probabfy. due to the mechanical distension produced progressive increase in the content of the duplicate. Bleeding occurred into the peritoneal cavity witho the rupture of a subserosal hematoma and this in turn was probably produced by the perforation of $\mathscr{\mathbb { Q }}$ the intestine and consequent penetration of $a \overrightarrow{\overrightarrow{0}}$ blood vessel. These vessels, as they pass over the 3 duplicate to reach the normal loop of intestine, are particularly vulnerable in this region.

Summary. A case of duplication of the intestine $\frac{0}{3}$ is described presenting, late in childhood, with:bleeding into the peritoneal cavity associated with 3 . a perforation in the duplicated segment. Resection of the duplication was carried out and an end-to- $\frac{3}{3}$ end anastomosis performed. The patient made an uneventful recovery.

I wish to thank Dr. P. R. Anthonis for per-을 mission to publish this case, and Mr. P. D. S. Ameraskera for the photograph.

\section{BIBLIOGRAPHY}

BREMER, J. L. (1944), Arch. Path. (Chicago), 38, 132.

FISHER, H. C. (1950), Arch. Surg. (Chicago), 6I, 957.

FRAZER, J. E. (1940), 'Manual of Embryology,' London, Baillière, Tindall \& Cox.

GROSS, R. E. (1953), 'The Surgery of Infancy and Childhood', Philadelphia, W. B. Saunders Co.

LADD, W. E., and GROSS, R. E. (1940), Surg. Gynec. Obstet., 70, 295.

NEEDHAM, J. (1942), 'Biochemistry and Morphogenesis,' Cambridge, University Press.

WOOLER, G. H. (1950), Brit. F. Surg., 37, 356. 